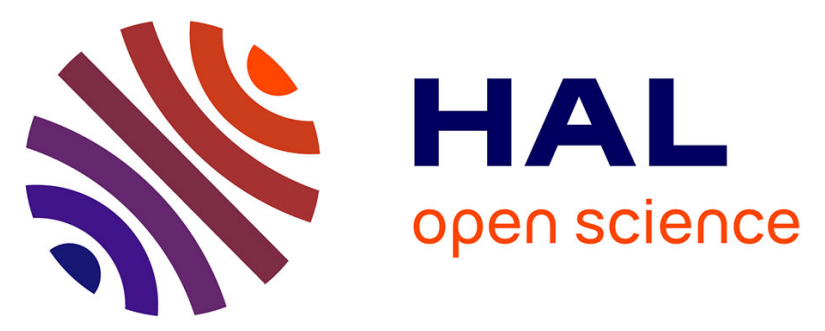

\title{
Decreasing worker size diversity does not affect colony performance during laboratory challenges in the ant Temnothorax nylanderi
}

T. Colin, C. Doums, R. Péronnet, Mathieu Molet

\section{- To cite this version:}

T. Colin, C. Doums, R. Péronnet, Mathieu Molet. Decreasing worker size diversity does not affect colony performance during laboratory challenges in the ant Temnothorax nylanderi. Behavioral Ecology and Sociobiology, 2017, 71 (6), pp.92. 10.1007/s00265-017-2322-4 . hal-01525790

\section{HAL Id: hal-01525790 \\ https://hal.sorbonne-universite.fr/hal-01525790}

Submitted on 22 May 2017

HAL is a multi-disciplinary open access archive for the deposit and dissemination of scientific research documents, whether they are published or not. The documents may come from teaching and research institutions in France or abroad, or from public or private research centers.
L'archive ouverte pluridisciplinaire HAL, est destinée au dépôt et à la diffusion de documents scientifiques de niveau recherche, publiés ou non, émanant des établissements d'enseignement et de recherche français ou étrangers, des laboratoires publics ou privés. 
Decreasing worker size diversity does not affect colony performance during laboratory challenges in the ant Temnothorax nylanderi

\author{
T. Colin ${ }^{1}$, C. Doums ${ }^{2,3}$, R. Péronnet ${ }^{1}$, M. Molet $^{1}$
}

Author details

1 Sorbonne Universités, UPMC Univ Paris 06, CNRS, Institute of Ecology and

Environnemental Sciences of Paris UMR7618, 7 quai St Bernard, 75252 Paris, France.

2 Institut de Systématique, Évolution, Biodiversité (ISYEB), EPHE, CNRS, UPMC Univ Paris 06,

MNHN, Sorbonne Universités ,45 rue Buffon, CP 39, 75005 Paris, France.

3 EPHE, PSL Research University, 75005 Paris, France

Corresponding author:

Mathieu Molet

Tel. +33 (0) 144272694

Fax. +33 (0) 144273516

E-mail : mathieu.molet@upmc.fr

Authors' contributions

TC collected colonies, reared them, performed the experiments and statistical analyses, and wrote the manuscript. $C D$ designed the study, contributed to statistical analysis and wrote the manuscript. RP collected colonies, and assisted in rearing and experiments. MM designed the study, wrote the manuscript, and supervised the project. All authors read and approved the final manuscript. 


\section{Acknowledgements}

This work was funded by Agence Nationale de la Recherche grant ANTEVO ANR-12-JSV7-000301. We thank Jeffrey Carbillet-Malherbe, Daphné Cahours, Alexandra Rocland and Morgane Bequet-Rennes for their help with colony collection, colony rearing and preliminary experiments and lan Billick for the information on polyandry and polygyny in Formica neorufibarbis. We thank two anonymous referees for their helpful comments on a previous version of the manuscript.

Keywords: canalization, division of labour, fitness, phenotypic plasticity, size variation 


\section{Abstract}

Within-colony phenotypic diversity can play an essential role in some eusocial insect taxa by increasing the performance of division of labor, thereby increasing colony fitness. Empirical studies of the effect of phenotypic diversity on colony fitness mostly focused on species with discrete castes (workers, soldiers) or with continuously and highly morphologically variable workers, which is not the most common case. Indeed, most species exhibit continuous but limited worker morphological variation. It is still unclear whether this variation impacts colony fitness. To test this, we reduced the worker size diversity in 25 colonies of the ant Temnothorax nylanderi and compared their performances to 25 control colonies. We reared these colonies in the laboratory and measured the effect of treatment (reduced diversity or control) and colony size (number of workers) on colony performance at six challenges, as well as on worker mortality and brood production. The reduction of worker size diversity did not affect colony performance nor mortality and brood production. As expected, colony performance and brood production increased with colony size. These results suggest that worker size diversity may not be under positive selection in this species, but rather the product of a lack of developmental canalization. We propose that social life could decrease the selective pressures maintaining developmental canalization, subsequently leading to higher size diversity without necessarily increasing colony performance. 
Significance statement

In social insects, nestmate size diversity is commonly thought to improve division of labour and colony performance. This has been clearly demonstrated in species with high size diversity, either discrete or continuous, but this is unclear in most of the social insects that exhibit low size diversity. We experimentally decreased worker size diversity in the ant Temnothorax nylanderi, a species with low worker size diversity. Reducing worker size diversity had no effect on colony performance, worker mortality or brood production. Our findings support the hypothesis that low size diversity is merely the product of developmental noise and is not necessarily adaptive. We propose that social life could relax the selective pressures maintaining developmental and social canalizations, subsequently leading to size diversity. 


\section{Introduction}

Phenotypic diversity, whether environmentally or genetically determined, plays a central role in the ecology and evolution of organisms. At the population scale, phenotypic diversity decreases intraspecific competition for food (Bolnick et al. 2011). At the individual scale, phenotypically differentiated cells facilitate simultaneous processes, such as digestion, respiration and movement and can improve the efficiency of the organism (Ispolatov et al. 2011). Similarly, within a social group, inter-individual diversity may improve division of labor among group members and enhance group efficiency (Pruitt and Richert 2010). In eusocial insects such as ants, bees, wasps and termites, phenotypic diversity among colony members is often associated with a strong division of labor. This division of labor often relies on morphological differences and is thought to be one of the keys to the ecological success of social insects (Wilson 1987). For example in ants, queens are large females that specialize in reproduction with developed ovaries and in dispersal with wings, while workers are smaller females that take care of non-reproductive tasks. Workers are cheaper to produce because they are small, they lack wings and in some species they also lack ovaries (Peeters 1997). These two phenotypes are examples of distinct 'castes' as they exhibit discrete morphological differences that are generated by distinct growth rules during development. They are generally the product of phenotypic plasticity (e.g. Sumner et al. 2006; Hunt et al. 2011; Linksvayer at al. 2011; but see Schwander et al. 2010).

Non-reproductive individuals within a colony can also be highly diversified in terms of body size and morphology. Morphological variation is often associated with behavioral specialization. This has been shown in species where workers are highly variable 
morphologically or where a discrete soldier caste exists such as harvester ants (Wilson 1984; Arnan et al. 2011), turtle ants (Powell 2009) and leaf-cutter ants (Evison et al. 2008) among others (e.g. Porter and Tschinkel 1986; Foster 1990; Hasegawa 1993a; Hasegawa 1993b; Passera et al. 1996; Harvey et al. 2000; Perry et al. 2004; Toth and Duffy 2008; Grüter et al. 2012). However, Fjerdingstad and Crozier (2006) highlighted the fact that worker size diversity is limited in the majority of ant species, including some of the most successful species. Of the 35 species that they studied, the majority of the body weight coefficient of variations of workers was lower than 0.2 (the coefficient of variation (CV) is a measure of variance that is independent of absolute size and is computed as the ratio between standard deviation and mean (Sokal and Rohlf 1970)). Very few studies investigated the potential benefits of having limited morphological diversity among workers and showed contrasted results. A positive effect of diversity was mainly observed in polyandrous and/or polygynous species for which morphological diversity can be associated with genetic diversity given that worker size has often been found to be heritable (Hughes et al. 2003; Rheindt et al. 2005; Schwander et al. 2005; Jaffé et al. 2007; Evison and Hughes 2011; Huang et al. 2013; Jandt and Dornhaus 2014; Table 1).

Focusing our attention on species with low level of morphological diversity could improve our understanding of how diversity evolved. As described above, a common thought is that selective pressures could favor an increase in morphological diversity through a better colonylevel efficiency and could subsequently lead to the evolution of worker subcastes even in species with low worker size diversity. Alternatively, size diversity could primarily evolve through relaxed selective pressures on worker size provided by social life. Relaxing selective pressures is known to decrease developmental canalization (the developmental processes that keep the phenotype constant in spite of genetic or environmental variation, see Debat 
and David 2001) and could hence increase worker size diversity (Hunt et al. 2011). In ants, worker size diversity could result from the active process of workers providing different environmental conditions to larvae and/or from developmental response of larvae to external environmental factors as observed in the ant Messor pergandei where larvae develop into workers of different sizes depending on the season (Rissing 1987). Whatever the mechanisms at the origin of worker size diversity, the first hypothesis (directional selection) predicts that worker size diversity should provide benefits to the colony even in species with low worker size diversity whereas the second hypothesis (relaxed selection) does not.

In this study, we tested whether size diversity affects colony fitness in the ant Temnothorax nylanderi, a species exhibiting continuous but limited worker size diversity. This species is widely distributed in Western Europe (Pusch et al. 2006), including urban areas, and is also easy to find, to identify, and to rear. It is mainly monogynous (Buschinger 1968; Foitzik and Heinze 2000) and monoandrous (Foitzik et al. 1997; Foitzik and Heinze 2000). Most of worker size diversity in this species should therefore result from phenotypic plasticity. To study the effects of continuous diversity on colony fitness and efficiency for particular tasks, researchers often focused on the function of larger and smaller workers in the colonies without manipulating worker diversity (e.g. Goulson et al. 2002; Spaethe and Weidenmüller 2002; Peat et al. 2005; Couvillon and Dornhaus 2010; Westling et al. 2014). In order to test whether colony fitness is affected by colony-level worker size diversity, including the colony-level emerging properties of worker size diversity and not only the functions of large and small workers, we manipulated colonies to reduce worker size diversity in test colonies while natural diversity was retained in control colonies. Colony fitness was indirectly assessed by challenging colonies with various tasks to perform, covering a wide range of usual colony activities such as emigration, solid and liquid food collection, nest construction and corpse removal. These 
colony-level tasks were chosen because they are likely to rely on worker size diversity as they classically involve large and small workers in other species. The ability to transport load was indirectly assessed through the foraging and nest construction tasks, a trait linked with worker size in ants (Kaspari 1996). The ability to defend the nest and resist to competition was indirectly assessed through emigration since a typical response of Temnothorax colonies to worker loss and predation is emigration to another nest (O'Shea-Wheller et al. 2015). We also tested colony resistance to cold temperatures. Brood production and worker survival at the end of the experiment were measured as fitness parameters that integrated the overall resistance of the colony to the various challenges.

\section{Material and Methods}

1) Colony sampling and rearing

We collected 128 colonies of T. nylanderi in November 2014 and January 2015 in the Bois de Vincennes forest (Paris, France $\left.48^{\circ} 50^{\prime} 22.14^{\prime \prime} \mathrm{N}, 2^{\circ} 26^{\prime} 51.96^{\prime \prime E}\right)$. Colonies were found in twigs. Back to the laboratory, the twigs were opened to force colonies to move into artificial nests made of two microscope slides separated by a $1 \mathrm{~mm}$ auto-adhesive plastic foam in which chambers had been cut out. Artificial nests were placed in $10 * 5 * 5 \mathrm{~cm}$ plastic rearing boxes (foraging areas) with fluon ${ }^{\circledR}$ on the walls to prevent ants from escaping. The boxes were placed in climatic chambers at $23^{\circ} \mathrm{C}$. Water was provided in tubes plugged with cotton. Every week half a mealworm soaked in honey was dropped in the foraging area as food. As soon as colonies had settled in their artificial nests, workers and larvae were counted under a 
stereomicroscope. We selected 50 colonies containing one queen and at least 40 workers for subsequent experiments.

\section{2) Experimental design}

Colonies were assigned randomly to a control or a test group, with a similar distribution of colony sizes between the two treatments. In colonies of the test group, we decreased the variance in worker size by removing $50 \%$ of workers, half (25\%) being the largest and half (25\%) being the smallest, using a stereoscopic microscope (Zeiss ${ }^{\circledR}$, x50 magnification). The assignment of workers to the 'small' or 'large' categories was done visually. In colonies of the control group, we randomly removed the same proportion of workers (50\%) in order to control for the reduction in colony size. To randomly remove the workers, we simply did not use a stereoscopic microscope, so that worker size could not be assessed visually. The validity of the method was confirmed at the end of the experiment: we did successfully remove larger and smaller workers in the test colonies while removing workers randomly in the control colonies (Wilcoxon rank sum test between large workers and remaining workers in test colonies $\mathrm{W}=575, P<0.001$; between small workers and remaining workers in test colonies $W=98, P<0.001$; between removed workers and remaining workers in control colonies $W=273$, $P=0.45)$. A potential issue is that small workers removed from the test colonies could be old minim workers from the founding phase; removing small workers would thus be equivalent to removing old workers, that is to say foragers. However we only included in our experiment large colonies containing more than 70 workers, so these were not young colonies and they were unlikely to contain workers from the founding phase. In addition, to our knowledge, incipient Temnothorax colonies do no produce minim workers and young Temnothorax colonies have a unimodal worker size distribution (Howard 2006). All removed workers were 
killed and stored in $70 \%$ ethanol to ultimately measure the coefficient of variation of worker size in the original natural colonies. All nymphs and last instar larvae were also removed from colonies, and the remaining brood was standardized to 150 larvae per colony. Accordingly, the nymphs weighed at the end of the experiment had developed from early instar larvae over the course of the experiment. Colonies were left undisturbed during six weeks before we began the challenges.

During five months, colonies of both groups were confronted to a series of six challenges (detailed in the following paragraph) in order to measure their efficiency at various tasks. To minimize observer bias, blinded methods were used when behavioral data were recorded as the experimenter did not know whether colonies belonged to the test or control group. Mortality and brood production were monitored at the end of the experiment. To do so, once a week, dead workers and fully developed pupae were picked out and stored in $70 \%$ ethanol or at $-25^{\circ} \mathrm{C}$ respectively. Removing fully developed pupae prevented worker emergence and maintained constant worker size diversity. At the end of the experiment, all brood was also stored. Mortality was measured as the percentage of dead workers whereas brood productivity was measured as the weight of all the pupae produced throughout the experiment.

\section{3) Challenges}

Six challenges were conducted sequentially in larger $31^{*} 24^{*} 10 \mathrm{~cm}$ plastic boxes with fluon ${ }^{\circledR}$ on the walls. The plastic boxes were cleaned with $96 \%$ ethanol between each experiment. Artificial nests were transferred from their rearing boxes into these challenge boxes 30 minutes before the beginning of the challenge. 
The first challenge was nest emigration following disturbance. We forced colonies to relocate, as their nests in nature are exposed to desiccation, flooding, or destruction (McGlynn 2012), causing frequent relocations (Sendova-Franks and Franks 1995). Although Temnothorax colonies can fight against competitors, predators and parasites, they commonly respond to such pressures by emigrating to another nest (Jongepier et al. 2014; O'Shea-Wheller et al 2015). Accordingly, emigration can be used as a measure of colony defense. An empty artificial nest was placed $20 \mathrm{~cm}$ away from the original nest containing the colony. The roof of the original nest was removed at $\mathrm{t}=0$ so that the colony would relocate to the new nest. Ants entering the new nest alone, carrying brood inside the new nest, carrying other workers inside the new nest or leaving the new nest were counted and summed up every two minutes. We then fitted the accumulation curves of the total number of larvae and workers to logistic curves using the "grofit" package for R v2.13.2 (R Development Core Team, 2008). Initial values were automatically estimated by the package, and data were fitted to the logistic function $y(t)=\frac{A}{1+\exp \left(\frac{4 \mu}{A} *(\lambda-t)+2\right)}$, with $A$ the maximum number of ants or brood units inside the new nest, $\mu$ the maximum slope i.e. the maximum speed of the emigration process, and $\lambda$ the lag-phase i.e. the time it took for emigration to start (Figure S1).

For the second challenge, we measured the performance of colonies at collecting liquid food. We cut $1 \times 1 \mathrm{~cm}$ pieces of aluminum sheets covered with Agipa ${ }^{\circledR}$ reinforcement labels and weighed them at a precision of $0.1 \mathrm{mg}$ using an Ohaus Pioneer ${ }^{\circledR}$ PA64C balance before and after adding $0.02 \mathrm{~mL}$ of a $0.2 \mathrm{~g} / \mathrm{mL}$ honey solution with a P200 Gilson's Pipetman Classic ${ }^{\circledR}$. Reinforcement labels were used to constrain the shape and size of the honey drop, in order to minimize the differences in evaporation between colonies. Aluminum sheets were then placed in the middle of the plastic boxes and left for three hours with the ants. Aluminum 
sheets were weighed at the end of the experiment to assess the honey solution intake of each colony. We then calculated the percentage of honey solution evaporated or drank by the ants.

The third challenge was to force colonies to build walls for their nests. Temnothorax ants prefer nests with a small entrance and build walls whenever the entrance is too large (Pratt and Pierce 2001). Colonies were forced to relocate to a new nest by removing the roof of their nest. The new nest was made of a space between two microscopes slides with only one wall. After two hours, we added $0.25 \mathrm{~g}$ of sawdust in the middle of the plastic boxes. Twenty-four hours later, we collected the sawdust carried inside the nests that the ants used to build walls, and we weighed it at a precision of $0.1 \mathrm{mg}$ using an Ohaus Pioneer ${ }^{\circledR}$ PA64C balance.

For the fourth challenge, we measured the performance of colonies at collecting solid food. Wingless Drosophila flies were reared, frozen at $-25^{\circ} \mathrm{C}$ for a few days and thawed 30 minutes before the beginning of the experiments. Five dead Drosophila were placed in the middle of the plastic boxes and we measured the time it took for the first three Drosophila to be brought into the nests.

The fifth challenge was to place ant corpses inside the nests to assess the efficiency of hygienic behaviors. Hygienic behaviors are an important component of colony response against pathogens (Cremer et al. 2007; Diez et al. 2014) and, like many other ants, Temnothorax workers carry dead nestmates outside (Renucci et al. 2011). A colony of T. nylanderi was frozen at $-25^{\circ} \mathrm{C}$ for 48 hours and thawed 30 minutes before the beginning of the experiments. At $t=0$, five dead ants from this colony were placed inside the artificial nests, close to the entrance. We recorded the time it took for all corpses to be discarded out of the nest. Challenges one to five can also be used to assess colony ability at transporting load, a trait that is typically linked with worker size (Kaspari 1996). 
The final challenge was to inflict a cold shock to the colonies. Colonies are exposed to negative temperatures during winter. Preliminary experiments on nine colonies showed a high resistance to cold with $51 \%$ of workers surviving after spending 30 minutes at $-25^{\circ} \mathrm{C}$. Colonies were thus frozen at $-25^{\circ} \mathrm{C}$ for 30 minutes and then placed at $23^{\circ} \mathrm{C}$ for 24 hours before counting dead workers. All surviving ants were then frozen to death and all ants were finally stored in $70^{\circ}$ ethanol.

4) Morphological measurements

The heads of the 8361 stored workers were separated from their bodies and stuck on doublesided tape. This included ants picked before the experiments ( $50 \%$ random, $25 \%$ largest and $25 \%$ smallest) and the ants used for the experiment including the ones that died during the experiment. Measuring the ants removed at the beginning of the experiment allowed us to test whether our manipulation was successful at decreasing worker size diversity in the test groups and in maintaining it in the control groups. Heads and a stage micrometer were photographed with the Nikon ${ }^{\circledR}$ D810 camera and the Nikkor ${ }^{\circledR} 105 \mathrm{~mm}$ macro lens with two Nikon ${ }^{\circledR}$ SB-26 flashes. Head widths were measured with ImageJ 1.48 available at http://imagej.nih.gov/ij/ (Abràmoff et al. 2004).

5) Statistical analysis

All statistics were conducted using R v3.2.3 available at http://www.R-project.org/. We first checked whether our manipulation of worker size diversity had the expected effects. To do so, we first compared worker size diversity before and after manipulation both in test and control groups using a paired Wilcoxon test. We also directly tested whether colonies of the test group had lower worker size diversity than colonies of the control group using a Wilcoxon 
test. Worker size diversity was assessed by estimating the coefficient of variation (Sokal and Rohlf 1970).

We tested whether the experimental reduction of worker size diversity affected colony performance using a MANOVA. Dependent variables were lag-phase duration for brood and workers before relocation ( $\lambda$ parameter in the equation of section 3 - Challenges), maximum speed of brood and workers relocation ( $\mu$ parameter in the equation of section $3-$ Challenges), time taken to bring three dead Drosophila back to the nest, quantity of liquid food collected, time taken to remove dead workers from the nest, mass of wood dust carried to build nest walls and the arcsine square root transformed percentage of ants that survived cold shock. Lag-phase duration for brood and workers were correlated (Pearson's product-moment correlation $\mathrm{t}=12.422, \mathrm{df}=48, P<0.001$ ), as well as maximum speed of brood and workers relocation (Pearson's product-moment correlation $t=7.001, d f=48, P<0.001$ ). To avoid multicollinearity, we only considered data on larvae for our analysis. Note though that the same qualitative results were obtained if keeping data on workers. We used treatment as an explanatory variable and colony size as a covariate. We confirmed the general result of the MANOVA by performing independent GLMs for each of the dependent variables of the MANOVA with treatment and colony size and their interaction as explanatory variables. For each model, we successively removed the interaction (if not significant) and the explanatory variables and performed pairwise comparison between the models with and without the factors of interest using a F-test.

We finally performed GLMs with natural mortality and mass of brood produced as dependent variables, and treatment, colony size and their interaction as explanatory variables. Natural mortality was expressed as the ratio of the number of ants that died over the course of the 
experiment, before the cold shock challenge, on the number of ants in the colony (binomial GLM).

The assumptions of all tests were validated. Regarding MANOVA, we checked normality (percentage of ants that survived cold shock was arcsine square root transformed to respect normality), absence of outliers, absence of multicollinearity (we removed data on worker emigration from our analysis), linearity and equality of covariance matrices. Regarding GLM, we checked homogeneity of variances and normality of the residuals visually.

\section{Results}

Across all colonies, worker head size varied from 0.45 to $0.70 \mathrm{~mm}$ ( 1.55 fold variation; $0.57 \mathrm{~mm} \pm 0.03 \mathrm{~mm}$ mean $\pm \mathrm{sd})$. As expected, the manipulation effectively decreased the coefficient of variation of worker size in the test group (Wilcoxon paired test $V=325, P<0.001$ ) but not in the control group (Wilcoxon paired test $V=184, P=0.58$ ) showing that random removal of workers did not affect worker size diversity in control colonies whereas nonrandom removal did (Fig. 1). Workers in control colonies were thus significantly more variable in size (1.68 times) than in test colonies (Wilcoxon test $W=81, P<0.001 ;$ Fig. 1 ).

Colonies successfully overcome all challenges. Emigrations took less than $166 \mathrm{~min}$ and brood was relocated in less than $158 \mathrm{~min}$. All three Drosophila were carried back to the nests in less than 150min (mean $=58 \mathrm{~min}$ ) and foragers of all colonies collected liquid food. All five dead workers were removed in less than $180 \mathrm{~min}$ (mean $=37 \mathrm{~min}$ ). Up to $0.0259 \mathrm{~g}$ of sawdust (mean 
$=0.0086 \mathrm{~g}$ ) was carried to the nests to build walls. Mortality after cold shock ranged from 8.4 to $100 \%($ mean $=78.1 \%)$.

The treatment had no effect on colony efficiencies (MANOVA with Pillai test, Pillai=0.076, $P=0.85$ ) but larger colonies were more efficient (Pillai=0.503, $P<0.001$; treatment and colony size interaction: Pillai=0.216, $P=0.17)$. Independent GLMs confirmed that there was no effect of treatment and showed that larger colonies were faster at relocating brood $(F=16, P<0.001)$, at bringing dead Drosophila back to the nest $(F=4.39, P=0.04)$ and at collecting liquid food $(F=20.97, P<0.001)$ (Fig. 2; Table 2). One interaction between colony size and treatment was significant regarding the mass of liquid food collected by the workers (Table 2). Performance increased quicker with colony size in colonies with reduced worker size diversity (Fig. 2). Small test colonies were less efficient than small control colonies, but large test colonies were more efficient than large control colonies.

There was no interaction between treatment and colony size on natural mortality (Deviance=$0.273, P=0.60$ ) and on mass of brood produced (Deviance $=-2.18 \mathrm{e}-5, P=0.63$ ). Treatment had no effect on natural mortality (Deviance $=-0.487, P=0.49$ ) and on the mass of brood produced (Deviance $=1.39 \mathrm{e}-4, P=0.43$ ). Colony size had no effect on natural mortality (Deviance $=-2.05 \mathrm{e}-$ $1, P=0.65$ ) but had a positive effect on the total mass of brood produced (Deviance $=6.40 \mathrm{e}-3$, $P<0.001)$.

\section{Discussion}


The aim of this study was to assess whether worker size diversity in T. nylanderi has a positive effect on colony fitness parameters. We found that experimentally reducing within-colony worker size diversity hardly had any effect on colony efficiency during various challenges, on natural worker mortality and on the mass of brood produced in the laboratory. These results are in agreement with the hypothesis that worker size diversity could evolve through relaxed selective pressures and do not support the hypothesis that worker size diversity is beneficial for the colony and is under positive colony-level selection. Our study is based on six challenges that encompass a wide range of tasks (emigration, foraging, hygienic behaviors, nest construction), resistance to an environmental stressor (cold) and two synthetic measurements of colony fitness (worker mortality and brood production). To our knowledge, this is the first study to investigate so many colony-level fitness components. The significant positive correlation between colony size and task efficiency found for half of the challenges irrespective of the treatment (control or test) confirm the commonly found positive relationship between colony efficiency and colony size (Hölldobler and Wilson 1990; Bourke and Franks 1995; Luque et al. 2013). Our study emphasizes the need to not overlook perform

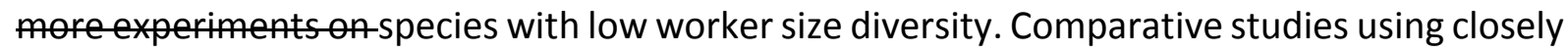
related species differing in their degree of worker size diversity would help shed light on the evolutionary processes that lead to the evolution of worker size diversity. Experiments including more tasks such as nest defence, or investigating colony fitness directly in the field should be performed to confirm our conclusion.

Our experimental design was based on the removal of $50 \%$ workers. This could have led to a collapse of colony organization. However we made sure that this manipulation did not affect the colonies too much and this was confirmed by our results. First, the size of our manipulated colonies remained within the natural range of colony sizes as it was not significantly different 
from the size of an independent sample of 376 unmanipulated colonies ( $t$-test $t=1.65$, $d f=80.72, P=0.10)$. Second, even though reduced, the worker size diversity in test colonies fell within or not far below the natural range of worker size diversity observed in field colonies (Fig. 1). Third, we did not observe any abnormal mortality either right after the removal of $50 \%$ of the workers, or throughout the experiment (only $9.3 \pm 6.0$ workers per colony died; mean \pm sd). Fourth, emigrations were not less efficient than in other studies; it took $68.1 \pm 14.8 \mathrm{~min}$ for our manipulated colonies to carry all the brood to their new nest $20 \mathrm{~cm}$ away, whereas Dornhaus and Franks (2006) found that unmanipulated colonies of T. albipennis required about $100 \mathrm{~min}$ to transport the last piece of brood to a new nest $35 \mathrm{~cm}$ away. Finally, our colonies kept performing everyday tasks and kept producing eggs and rearing brood to adulthood. In conclusion, our colonies of $T$. nylanderi were resilient to worker loss. This is not a surprise in this genus: Dornhaus and Franks (2006; with T. albipennis) and Pinter-Wollman et al (2012; with T. albipennis and T. rugatulus) performed massive worker removals (75\% and $20 \%$ respectively) and found that colonies still behaved normally. The six weeks window between manipulation and the beginning of the experiments allowed colonies to recover and resume normal activity.

Our results are in agreement with those obtained by Modlmeier and Foitzik (2011) on Temnothorax longispinosus. Based on a correlative approach in the laboratory, they found no link between worker size diversity and per-capita productivity despite significant differences in worker size diversity among field colonies. To our knowledge, a significant effect of worker size diversity on colony fitness in species with limited worker size diversity has only been demonstrated in polygynous and/or polyandrous species (see table 1). In these species, the manipulation of worker size diversity might have also affected the within-colony level of genetic diversity if worker size exhibits some level of heritability. Hence, although the 
importance of worker size diversity for colony performance has been demonstrated in species with high continuous worker size diversity, worker subcastes or soldiers (e.g. Passera et al. 1996, other references in introduction), the benefits are far from clear in species with limited worker size diversity (references in Table 1).

The absence of a treatment effect in our experiment cannot be explained by a lack of division of labor as Temnothorax workers have been shown to specialize in particular tasks (e.g. Dornhaus et al. 2009; Pinter-Wollman et al. 2012) and behavioral diversity in brood care and exploration has been shown to positively correlate with colony productivity (Modlmeier et al. 2012). However, little is known about the link between division of labor and worker size in Temnothorax. Only foraging has been assessed, in two studies, and larger workers were more likely to forage than smaller workers (Herbers and Curningham 1983; Westling et al. 2014). In our study, the only task that was affected by the treatment (through a significant interaction between colony size and treatment) was foraging for liquid food. Small test colonies are less efficient than small control colonies, but large test colonies are more efficient than large control colonies. Why colonies with reduced worker size diversity would become more efficient at this task relative to control colonies as colony size increases is difficult to explain. Considering that test colonies have a higher proportion of medium workers than control colonies, one possible explanation would be that medium workers are more efficient at collecting liquid food than small and large workers. This result may also simply correspond to a type 2 error. More experiments are needed to fully explore the role of worker size on task propensity and efficiency in Temnothorax.

If Temnothorax colonies do not benefit from worker size diversity in terms of division of labor, what other selective pressures could favor such diversity? First, worker size is known to affect 
individual resistance to environmental stressors such as cold shock or starvation (Modlmeier et al. 2013). Accordingly, worker size diversity could help colonies face different stressors (Couvillon and Dornhaus 2010 in bumblebees). For instance, if large workers are advantageous for starving colonies (Modlmeier et al. 2013 in T. nylanderi) whereas small workers are advantageous when facing another stressor, worker size diversity could provide benefits to colonies exposed to various stress sources. In addition, even though small workers are less efficient than large workers, it can still be advantageous for the colony to produce small workers when resources are limited. Indeed, as solitary organisms, colonies face a size/number trade off in offspring production (e.g. Hasegawa and Imai 2012), so producing more small workers than few large ones could sometimes allow colonies to increase growth rate. This is particularly true for incipient colonies that are known to produce nanitic workers in various species (e.g. Porter and Tschinkel 1986). Stressful environmental conditions could therefore select for worker size diversity. In our experiment, we did not find any treatment effect on colony recovery from a cold shock, but confronting colonies to various environmental stressors would be an interesting perspective. Second, in most ant species including Temnothorax species, workers are able to produce male eggs through arrhenotokous parthenogenesis. In Temnothorax, workers rarely reproduce in the presence of the queen, but conflicts over male production among workers quickly start after queen removal (Heinze et al. 1997). In ants, larger workers have more ovarioles and are more fertile (e.g. Dietemann et al. 2002; Clémencet et al. 2008). In Temnothorax, workers vary in ovariole number and workers with more ovarioles are more likely to develop their ovaries following queen removal (Heinze et al. 1997). The distribution of worker size within a colony might therefore not only reflect colony-level selection but also individual-level selection and intra- 
colonial conflicts. Large workers could thus sometimes evolve from selfish egg-laying workers (Gobin and Ito 2003).

Finally, as pointed out in the introduction, worker size diversity might simply not be advantageous and result from relaxed selective pressures on worker size because of social buffering. Social buffering is a colony-level property that allows for the regular production and survival of divergent phenotypes. These phenotypes do not inflict significant costs on colony fitness because they are diluted among nestmates (Molet et al. 2012). Social buffering is therefore expected to reduce selective pressures for canalization, i.e. the mechanisms that keep the phenotype constant in spite of genetic or environmental variation (see Debat and David 2001 for a review of the definitions of canalization). Social buffering could therefore enhance the production of divergent phenotypes, including slightly smaller and larger workers, because these inflict no colony-level cost while avoiding the potential cost of canalization. In social insects, canalization of the adult phenotype during brood development is achieved by both the individual developmental process of larvae (Debat and David 2011) and the social behavior of nestmate workers (Linksvayer et al. 2011). For instance, in cellbuilding social insects, the size of individuals is controlled by the quantity of food provided by workers in the cell (Karsai and Hunt 2002; Kapheim et al. 2011; Linksvayer et al. 2011; Brand and Chapuisat 2012) and not only by the ability of larvae to grow. Many species can also control the abiotic environment experienced by larvae; for example, Apis mellifera honeybees, red wood ants of the Formica rufa group and Temnothorax ants limit temperature fluctuations in their nests (Rosengren et al. 1987; Fahrenholz et al. 1989; Karlik et al. 2016). Temnothorax ants, despite nesting in small preformed nests, can display social canalization: under deteriorated environmental conditions, colonies readily migrate to better nests (Dornhaus et al. 2004). Social canalization and its potential cost would deserve more attention in species 
with low worker size diversity. Because our study revealed no effect of worker size diversity on colony performance, it emphasizes the idea that the degree of worker size diversity found in colonies of social insects could result from a balance between the costs and benefits of social canalization and not only from colony-level benefits of division of labor as classically admitted in literature.

\section{Ethical Statement}

- Funding

This work was funded by Agence Nationale de la Recherche grant ANTEVO ANR-12-JSV7-000301.

- Conflict of Interest

The authors declare that they have no conflict of interest.

- Ethical approval

All applicable international, national, and/or institutional guidelines for the care and use of animals were followed.

- Data availability statement

The dataset analysed during the current study is available from the corresponding author on reasonable request.

\section{References}

Abràmoff MD, Magalhães PJ, Ram SJ (2004) Image processing with imageJ. Biophotonics Int 11:36-41. Arnan X, Ferrandiz-Rovira M, Pladevall C, Rodrigo A (2011) Worker size-related task partitioning in the foraging strategy of a seed-harvesting ant species. Behav Ecol Sociobiol 65:1881-1890.

Bershers SN, Traniello JFA (1994) The Adaptiveness of Worker Demography in the Attine Ant Trachymyrmex septentrionalis. Ecology 75:763-775.

Billick I (2002) The relationship between the distribution of worker sizes and new worker production in the ant Formica neorufibarbis. Oecologia 132:244-249. 
Billick I, Carter C (2007) Testing the importance of the distribution of worker sizes to colony performance in the ant species Formica obscuripes forel. Insectes Soc 54:113-117.

Bolnick DI, Amarasekare P, Araujo MS, et al (2011) Why intraspecific trait variation matters in community ecology. Trends Ecol Evol 26:183-192.

Bourke AFG, Franks NR (1995) Social Evolution in Ants. Princeton University Press, Princeton.

Brand N, Chapuisat M (2012) Born to be bee, fed to be worker? The caste system of a primitively eusocial insect. Front Zool 9:35.

Brown WD, Keller L (2002) Queen recruitment and split sex ratios in polygynous colonies of the ant Formica exsecta. Ecol Lett 5:102-109.

Buschinger A (1968) Mono-und polygynie bei arten der gattung Leptothorax Mayr (Hymenoptera Formicidae). Insectes Soc 15:217-225.

Charbonneau D, Hillis N, Dornhaus A (2015) "Lazy" in nature: ant colony time budgets show high "inactivity" in the field as well as in the lab. Insectes Soc 62:31-35.

Clémencet J, Rome Q, Fédérici P, Doums C (2008) Aggressions and size-related fecundity of queenless workers in the ant Cataglyphis cursor. Naturwissenschaften 95:133-139.

Cole BJ, Wiernasz DC (1999) The Selective Advantage of Low Relatedness. Science (80- ) 285:891-893.

Couvillon MJ, Dornhaus A (2010) Small worker bumble bees (Bombus impatiens) are hardier against starvation than their larger sisters. Insectes Soc 57:193-197.

Cremer S, Armitage SAO, Schmid-Hempel P (2007) Social Immunity. Curr Biol 17:693-702.

Debat V, David P (2001) Mapping phenotype: canalization, plasticity and developmental stability. Trends Ecol Evol 16:555-561.

Dietemann V, Hölldobler B, Peeters C (2002) Caste specialization and differentiation in reproductive potential in the phylogenetically primitive ant Myrmecia gulosa. Insectes Soc 49:289-298.

Diez L, Lejeune P, Detrain C (2014) Keep the nest clean: survival advantages of corpse removal in ants. Biol Lett 10:20140306.

Dornhaus A, Franks NR, Hawkins RM, Shere HNS (2004) Ants move to improve: Colonies of Leptothorax albipennis emigrate whenever they find a superior nest site. Anim Behav 67:959-963.

Dornhaus A, Franks NR (2006). Colony size affects collective decision-making in the ant Temnothorax albipennis. Insectes Soc 53:420-427.

Dornhaus A, Holley J, Franks N (2009) Larger colonies do not have more specialized workers in the ant Temnothorax albipennis. Behav Ecol 20:922-929.

Evison SEF, Hart AG, Jackson DE (2008) Minor workers have a major role in the maintenance of leafcutter ant pheromone trails. Anim Behav 75:963-969.

Evison SEF, Hughes WOH (2011) Genetic caste polymorphism and the evolution of polyandry in Atta leaf-cutting ants. Naturwissenschaften 98:643-649.

Eyer P-A, Freyer J, Aron S (2013) Genetic polyethism in the polyandrous desert ant Cataglyphis cursor. Behav Ecol 24:144-151. 
Fahrenholz L, Lamprecht I, Schricker B (1989) Thermal investigations of a honey bee colony: thermoregulation of the hive during summer and winter and heat production of members of different bee castes. J Comp Physiol B 159:551-560.

Fjerdingstad EJ, Crozier RH (2006) The Evolution of Worker Caste Diversity in Social Insects. Am Nat 167:390-400.

Foitzik S, Haberl M, Gadau J, Heinze J (1997) Mating frequency of Leptothorax nylanderi ant queens determined by microsatellite analysis. Insectes Soc 44:219-227.

Foitzik S, Heinze J (2000) Intraspecific parasitism and split sex ratios in a monogynous and monandrous ant (Leptothorax nylanderi ). Behav Ecol Sociobiol 47:424-431.

Foster W. (1990) Experimental evidence for effective and altruistic colony defence against natural predators by soldiers of the gall-forming aphid Pemphigus spyrothecae (Hemiptera : Pemphigidae). Behav Ecol Sociobiol 27:421-430.

Fournier D, Battaille G, Timmermans I, Aron S (2008) Genetic diversity, worker size polymorphism and division of labour in the polyandrous ant Cataglyphis cursor. Anim Behav 75:151-158.

Gobin B, Ito F (2003) Sumo wrestling in ants: Major workers fight over male production in Acanthomyrmex ferox. Naturwissenschaften 90:318-21.

Goulson D, Peat J, Stout JC, et al (2002) Can alloethism in workers of the bumblebee, Bombus terrestris, be explained in terms of foraging efficiency? Anim Behav 64:123-130.

Greenberg L, Fletcher DJC, Vinson SB (1985) Differences in worker size and mound distribution in monogynous and polygynous colonies of the fire ant Solenopsis invicta Buren. J Kansas Entomol Soc 58:9-18.

Grüter C, Menezes C, Imperatriz-Fonseca VL, Ratnieks FLW (2012) A morphologically specialized soldier caste improves colony defense in a neotropical eusocial bee. Proc Natl Acad Sci U S A 109:11821186.

Harvey JA, Corley LS, Strand MR (2000) Competition induces adaptive shifts in caste ratios of a polyembryonic wasp. Nature 406:183-186.

Hasegawa E (1993a) Caste specialization in food storage in the dimorphic ant Colobopsis nipponicus (Wheeler). Insectes Soc 40:261-271.

Hasegawa E (1993b) Nest defense and early production of the major workers in the dimorphic ant Colobopsis nipponicus (Wheeler) (Hymenoptera : Formicidae). Behav Ecol Sociobiol 33:73-77.

Hasegawa E, Imai S (2012) A trade-off between number and size within the first workers of the ant Camponotus japonicus. J Ethol 30, 201-204.

Herbers JM, Cunningham M (1983) Social organization in Leptothorax longispinosus Mayr. Anim Behav 31:759-771.

Heinze J, Puchinger W, Hölldobler B (1997) Worker reproduction and social hierarchies in Leptothorax ants. Anim Behav 54:849-64.

Hölldobler B, Wilson EO (1990) The Ants. Harvard University Press, Cambridge.

Howard KJ (2006) Three queen morphs with alternative nest-founding behaviors in the ant, Temnothorax longispinosus. Insectes Soc 53, 480-488. 
Huang MH, Wheeler DE, Fjerdingstad EJ (2013) Mating system evolution and worker caste diversity in Pheidole ants. Mol Ecol 22:1998-2010.

Hughes WOH, Sumner S, Borm S Van, Boomsma JJ (2003) Worker caste polymorphism has a genetic basis in Acromyrmex leaf-cutting ants. Proc Natl Acad Sci 100:9394-9397.

Hunt BG, Ometto L, Wurm Y, et al (2011) Relaxed selection is a precursor to the evolution of phenotypic plasticity. Proc Natl Acad Sci 108:15936-15941.

Hunt JH, Karsai I (2002) Food Quantity Affects Traits of Offspring in the Paper Wasp Polistes metricus (Hymenoptera : Vespidae ). Popul Ecol 31:99-106.

Ispolatov I, Ackermann M, Doebeli M (2012) Division of labour and the evolution of multicellularity. Proc R Soc B Biol Sci 279:1768-1776.

Jaffé R, Kronauer DJC, Kraus FB, et al (2007) Worker caste determination in the army ant Eciton burchellii. Biol Lett 3:513-516.

Jandt JM, Dornhaus A (2014). Bumblebee response thresholds and body size: does worker diversity increase colony performance? Anim Behav 87:97-106.

Jones JC (2004) Honey Bee Nest Thermoregulation: Diversity Promotes Stability. Science (80) 305:402404.

Jongepier E, Kleeberg I, Job S, Foitzik S (2014). Collective defence portfolios of ant hosts shift with social parasite pressure. Proc Biol Sci 281:20140225.

Kapheim KM, Bernal SP, Smith AR, et al (2011) Support for maternal manipulation of developmental nutrition in a facultatively eusocial bee, Megalopta genalis (Halictidae). Behav Ecol Sociobiol 65:1179-1190.

Karlik J, Epps MJ, Dunn RR, Penick CA, Foster S (2016) Life inside an acorn: How microclimate and microbes influence nest organization in Temnothorax ants. Ethology 122:790-797.

Karsai I, Hunt JH (2002) Food quantity affects traits of offspring in the paper wasp Polistes metricus (Hymenoptera: Vespidae ). Popul Ecol 31:99-106.

Kaspari M (1996) Worker size and seed size selection by harvester ants in a Neotropical forest. Oecologia 105:397-404.

Keller L, Reeve HK (1994) Genetic Variability, Queen Number, and Polyandry in Social Hymenoptera. Evolution 48:694-704.

Lawson LP, Vander Meer RK, Shoemaker D (2012) Male reproductive fitness and queen polyandry are linked to variation in the supergene Gp-9 in the fire ant Solenopsis invicta. Proc R Soc B Biol Sci 279:3217-3222.

Linksvayer TA, Kaftanoglu O, Akyol E, et al (2011) Larval and nurse worker control of developmental plasticity and the evolution of honey bee queen-worker dimorphism. J Evol Biol 24:1939-1948.

Londe S, Monnin T, Cornette R, et al (2015) Phenotypic plasticity and modularity allow for the production of novel mosaic phenotypes in ants. Evodevo 6:36.

Luque GM, Giraud T, Courchamp F (2013) Allee effects in ants. J Anim Ecol 82:956-965.

Macom TE, Porter SD (1996) Comparison of Polygyne and Monogyne Red Imported Fire Ant 
(Hymenoptera: Formicidae) Population Densities. Ann Entomol Soc Am 89:535-543.

Mattila HR, Seeley TD (2007) Genetic Diversity in Honey Bee Colonies Enhances Productivity and Fitness. Science (80- ) 317:362-364.

McGlynn TP (2012) The Ecology of Nest Movement in Social Insects. Annu Rev Entomol 57:291-308.

Mehdiabadi NJ, Shultz TR (2009) Natural history and phylogeny of the fungus-farming ants (Hymenoptera : Formicidae : Myrmicinae : Attini). Myrmecological News 13:37-55.

Modlmeier AP, Liebmann JE, Foitzik S (2012) Diverse societies are more productive: a lesson from ants. Proc R Soc B Biol Sci 279:2142-2150.

Modlmeier AP, Foitzik S (2011) Productivity increases with variation in aggression among group members in Temnothorax ants. Behav Ecol 22:1026-1032.

Modlmeier AP, Foitzik S, Scharf I (2013) Starvation endurance in the ant Temnothorax nylanderi depends on group size, body size and access to larvae. Physiol Entomol 38, 89-94.

Molet M, Wheeler DE, Peeters C (2012) Evolution of Novel Mosaic Castes in Ants: Modularity, Phenotypic Plasticity, and Colonial Buffering. Am Nat 180:328-341.

O'Shea-Wheller TA, Sendova-Franks AB, Franks NR (2015) Differentiated anti-predation responses in a superorganism. PLoS One 10:1-10.

Okada Y, Plateaux L, Peeters C (2013) Morphological variability of intercastes in the ant Temnothorax nylanderi: Pattern of trait expression and modularity. Insectes Soc 60:319-328.

Page R, Robinson G, Fondrk K, Nasr M (1995) Effects of worker genotypic diversity on honey bee colony development and behavior ( Apis mellifera L.). Behav Ecol Sociobiol 36:387-396.

Passera L, Roncin E, Kaufmann B, Keller L (1996) Increased soldier production in ant colonies exposed to intraspecific competition. Nature 379:630-631.

Peat J, Tucker J, Goulson D (2005) Does intraspecific size variation in bumblebees allow colonies to efficiently exploit different flowers? Ecol Entomol 30:176-181.

Peeters C (1997) Morphologically "primitive" ants: comparative review of social characters, and the importance of queen-worker dimorphism. In: The evolution of social behavior in insects and arachnids. Cambridge University Press, Cambridge. pp 372-391.

Perry SP, Chapman TW, Schwarz MP, Crespi BJ (2004) Proclivity and effectiveness in gall defence by soldiers in five species of gall-inducing thrips: Benefits of morphological caste dimorphism in two species (Kladothrips intermedius and K. habrus). Behav Ecol Sociobiol 56:602-610.

Pinter-Wollman N, Hubler J, Holley JA, Franks N, Dornhaus A (2012) How is activity distributed among and within tasks in Temnothorax ants? Behav Ecol Sociobiol 66:1407-1420.

Porter SD, Tschinkel WR (1986) Adaptive value of nanitic workers in newly founded red imported fire ant colonies (Hymenoptera: Formicidae). Ann Entomol Soc Am 79:723-726.

Porter SD, Tschinkel WR (1985) Fire ant polymorphism (Hymenoptera: Formicidae): factors affecting worker size. Behav Ecol Sociobiol 16:381-386.

Powell S (2009) How ecology shapes caste evolution: Linking resource use, morphology, performance and fitness in a superorganism. J Evol Biol 22:1004-1013. 
Powell S, Franks NR (2005) Caste evolution and ecology: a special worker for novel prey. Proc R Soc B Biol Sci 272:2173-2180.

Pratt SC, Pierce NE (2001) The cavity-dwelling ant Leptothorax curvispinosus uses nest geometry to discriminate between potential homes. Anim Behav 62:281-287.

Pruitt JNJ, Riechert SSE (2011) How within-group behavioural variation and task efficiency enhance fitness in a social group. Proc R Soc London Ser B-Biological Sci 278:1209-15.

Pusch K, Heinze J, Foitzik S (2006) The influence of hybridization on colony structure in the ant species Temnothorax nylanderi and T. crassispinus. Insectes Soc 53:439-445.

R Development Core Team (2008) R: A language and environment for statistical computing. R Foundation for Statistical Computing, Vienna, Austria. URL

Renucci M, Tirard A, Provost E (2011) Complex undertaking behavior in Temnothorax lichtensteini ant colonies: From corpse-burying behavior to necrophoric behavior. Insectes Soc 58:9-16.

Rheindt FE, Strehl CP, Gadau J (2005) A genetic component in the determination of worker polymorphism in the Florida harvester ant Pogonomyrmex badius. Insectes Soc 52:163-168.

Rosengren R, Fortelius W, Lindström K, et al (1987) Phenology and causation of nest heating and thermoregulation in red wood ants of the Formica rufa group studied in coniferous forest habitats in Southern Finland. Ann Zool Fennici 24:147-155.

Schwander T, Rosset H, Chapuisat M (2005) Division of labour and worker size polymorphism in ant colonies: The impact of social and genetic factors. Behav Ecol Sociobiol 59:215-221.

Schwander T, Lo N, Beekman M, Oldroyd BP, Keller L (2010) Nature versus nurture in social insect caste differentiation. Trends Ecol Evol 25:275-282.

Sendova-Franks a B, Franks NR (1995) Division-of-Labor in a Crisis - Task Allocation During Colony Emigration in the Ant Leptothorax unifasciatus (Latr). Behav Ecol Sociobiol 36:269-282.

Sokal RR, Rohlf FJ (1970) Biometry. The Principles and Practice of Statistics in Biological Research. Science (80- ) 167:165.

Spaethe J, Weidenmüller A (2002) Size variation and foraging rate in bumblebees (Bombus terrestris). Insectes Soc 49:142-146.

Sumner S, Pereboom JJM, Jordan WC (2006) Differential gene expression and phenotypic plasticity in behavioural castes of the primitively eusocial wasp, Polistes canadensis. Proc R Soc B Biol Sci 273:19-26.

Tarpy DR (2003) Genetic diversity within honeybee colonies prevents severe infections and promotes colony growth. Proc R Soc B Biol Sci 270:99-103.

Tarpy DR, Seeley TD (2006) Lower disease infections in honeybee (Apis mellifera) colonies headed by polyandrous vs monandrous queens. Naturwissenschaften 93:195-199.

Tóth E, Duffy JE (2008) Influence of sociality on allometric growth and morphological differentiation in sponge-dwelling alpheid shrimp. Biol J Linn Soc 94:527-540.

Van Buskirk J, Steiner UK (2009) The fitness costs of developmental canalization and plasticity. J Evol Biol 22:852-860. 
Westling JN, Harrington K, Bengston S, Dornhaus A (2014) Morphological differences between extranidal and intranidal workers in the ant Temnothorax rugatulus, but no effect of body size on foraging distance. Insectes Soc 61:367-369.

Wiernasz DC, Perroni CL, Cole BJ (2004) Polyandry and fitness in the western harvester ant, Pogonomyrmex occidentalis. Mol Ecol 13:1601-1606.

Wilson EO (1984) The relation between caste ratios and division of labor in the ant genus Pheidole (Hymenoptera: Formicidae). Behav. Ecol. Sociobiol. 16:89-98.

Wilson EO (1987) Causes of Ecological Success: The Case of the Ants. J Anim Ecol 56:1-9. 
1 Table 1 Continuous but limited within-colony worker size diversity in social insects has various effects on colony fitness based on literature.

\begin{tabular}{|c|c|c|c|c|c|}
\hline Species & Polyandry / Polygyny & Effect of worker size diversity & Approach & Quantification of diversity & Reference \\
\hline $\begin{array}{l}\text { Temnothorax } \\
\text { longispinosus }\end{array}$ & $\begin{array}{l}\text { No/No or rare } \\
\text { (Foitzik and Heinze 2000) }\end{array}$ & $\begin{array}{l}\text { No effect on colony weight but positive } \\
\text { effect of behavioral diversity on colony } \\
\text { weight. }\end{array}$ & Correlation & $\begin{array}{l}\text { Head width variation: factor 1.3. + } \\
\text { variations in brood care, exploration } \\
\text { and aggression }\end{array}$ & $\begin{array}{l}\text { Modlmeier and Foitzik } \\
\text { (2011) Modlmeier et al. } \\
\text { (2012) }\end{array}$ \\
\hline $\begin{array}{l}\text { Formica } \\
\text { neorufibarbis }\end{array}$ & $\begin{array}{l}\text { ?/Yes } \\
\text { (Ian Billick, pers. comm.) }\end{array}$ & $\begin{array}{l}\text { No effect on number of cocoon produced } \\
\text { per worker. }\end{array}$ & Experiment & $\begin{array}{l}\text { Head width variation from } 0.80 \text { to } \\
1.45 \mathrm{~mm} \text { : factor } 1.8\end{array}$ & Billick (2002) \\
\hline $\begin{array}{l}\text { Trachymyrmex } \\
\text { septentrionalis }\end{array}$ & $\begin{array}{l}\text { ?/Occasional } \\
\text { (Mehdiabadi and Schultz 2009) }\end{array}$ & $\begin{array}{l}\text { Positive or negative effect on biomass of } \\
\text { sexuals produced depending on } \\
\text { population. }\end{array}$ & Correlation & $\begin{array}{l}\text { Head width variation from } 0.75 \text { to } \\
1.25 \mathrm{~mm} \text { : factor } 1.7\end{array}$ & $\begin{array}{l}\text { Bershers and Traniello } \\
\text { (1994) }\end{array}$ \\
\hline Solenopsis invicta & $\begin{array}{l}\text { Yes/Yes (Lawson et al. } \\
\text { 2012)/(Macom and Porter 1996) }\end{array}$ & $\begin{array}{l}\text { Positive effect on mass of brood } \\
\text { produced per gram of worker. }\end{array}$ & Experiment & $\begin{array}{l}\text { Head width variation from } 0.63 \text { (or less) } \\
\text { to } 1.35 \mathrm{~mm} \text { (or more): factor } 2.14 \text { at } \\
\text { least }\end{array}$ & $\begin{array}{l}\text { Porter and Tschinkel } \\
\text { (1985) }\end{array}$ \\
\hline Formica obscuripes & $\begin{array}{l}\text { Yes/Yes (Keller and Reeve } \\
\text { 1994)/(Brown and Keller 2002) }\end{array}$ & $\begin{array}{l}\text { Positive effect on dry mass of adult } \\
\text { workers. }\end{array}$ & Experiment & $\begin{array}{l}\text { Head width variation from } 0.94 \text { to } \\
2.1 \mathrm{~mm} \text { : factor } 2.2\end{array}$ & Billick and Carter (2007) \\
\hline
\end{tabular}


3 Table 2 Analysis of the effect of colony size and worker size diversity on the six variables

4 taken separately using GLM and GLMER.

5

\begin{tabular}{|c|c|c|c|c|c|c|c|}
\hline & \multirow{3}{*}{ Analysis } & \multirow{2}{*}{\multicolumn{2}{|c|}{ Colony size }} & \multirow{2}{*}{\multicolumn{2}{|c|}{ Treatment }} & \multirow{2}{*}{\multicolumn{2}{|c|}{ Interaction }} \\
\hline & & & & & & & \\
\hline & & $\begin{array}{c}\text { Statistical } \\
\text { value }\end{array}$ & P-value & $\begin{array}{c}\text { Statistical } \\
\text { value }\end{array}$ & P-value & $\begin{array}{l}\text { Statistical } \\
\text { value }\end{array}$ & P-value \\
\hline $\begin{array}{l}\text { Brood relocation } \\
\text { lag-phase time }\end{array}$ & $\begin{array}{l}\text { GLM } \\
\log (y)\end{array}$ & $\begin{array}{c}0.53 \\
F\end{array}$ & 0.39 & $\begin{array}{c}1.00 \mathrm{e}-3 \\
F\end{array}$ & 0.97 & $\begin{array}{c}0.52 \\
F\end{array}$ & 0.47 \\
\hline $\begin{array}{l}\text { Brood relocation } \\
\text { speed }\end{array}$ & GLM & $\begin{array}{l}16 \\
F\end{array}$ & $2.22 \mathrm{e}-4$ & $\begin{array}{c}1.22 \\
F\end{array}$ & 0.27 & $\begin{array}{c}0.30 \\
F\end{array}$ & 0.58 \\
\hline $\begin{array}{l}\text { Time required to } \\
\text { bring } 3 \text { dead } \\
\text { Drosophila back to } \\
\text { the nest }\end{array}$ & GLM & $\begin{array}{c}4.39 \\
F\end{array}$ & 0.04 & $\begin{array}{c}0.71 \\
F\end{array}$ & 0.40 & $\begin{array}{c}1.36 \\
F\end{array}$ & 0.25 \\
\hline $\begin{array}{l}\text { Mass of liquid food } \\
\text { intake }\end{array}$ & GLM & $\begin{array}{c}20.97 \\
F\end{array}$ & $3.43 e-5$ & $\begin{array}{c}0.55 \\
F\end{array}$ & 0.46 & $\begin{array}{c}8.56 \\
F\end{array}$ & $5.32 \mathrm{e}-3$ \\
\hline $\begin{array}{l}\text { Time required for } \\
\text { the removal of alien } \\
\text { worker corpses }\end{array}$ & GLM & $\begin{array}{c}1.71 \\
F\end{array}$ & 0.19 & $\begin{array}{c}0.02 \\
F\end{array}$ & 0.89 & $\begin{array}{c}0.01 \\
F\end{array}$ & 0.91 \\
\hline $\begin{array}{l}\text { Mass of sawdust } \\
\text { carried }\end{array}$ & GLM & $\begin{array}{c}0.21 \\
F\end{array}$ & 0.65 & $\begin{array}{c}0.08 \\
F\end{array}$ & 0.78 & $\begin{array}{c}0.22 \\
F\end{array}$ & 0.64 \\
\hline $\begin{array}{l}\text { Mortality after } \\
\text { freezing }\end{array}$ & $\begin{array}{l}\text { Binomial } \\
\text { GLMER }\end{array}$ & $\begin{array}{l}1.58 \\
\text { Chisq }\end{array}$ & 0.21 & $\begin{array}{l}1.52 \\
\text { Chisq }\end{array}$ & 0.22 & $\begin{array}{l}1.36 \\
\text { Chisq }\end{array}$ & 0.24 \\
\hline
\end{tabular}


9 Fig. 1 Boxplot of the coefficient of variation (CV) of worker head width in the field and in the laboratory, for control and test groups. Boxes show median, quartiles and extremes. CV did not differ between control colonies from field to laboratory, but CV was successfully lowered in test colonies from field to laboratory due to the removal of large and small workers had been removed. The dashed lines connect the same colony before and after treatment.

Fig. 2 The experimental reduction of worker size diversity had no effect on colony efficiency at any task. Test colonies are represented by empty circles and control colonies by black circles. Independent GLMs showed that larger colonies were faster at relocating brood (a), at bringing dead Drosophila back to the nest (c), at collecting liquid food (d) and they produced significantly more brood mass (h). Mortality after freezing (g) and natural mortality (i) are represented as percentage to facilitate interpretation of the results. The interaction between colony size and treatment for the mass of liquid food collected is shown by the two dotted regression lines (f). Statistics are presented in Table 2 and in the results. 
Fig. 1

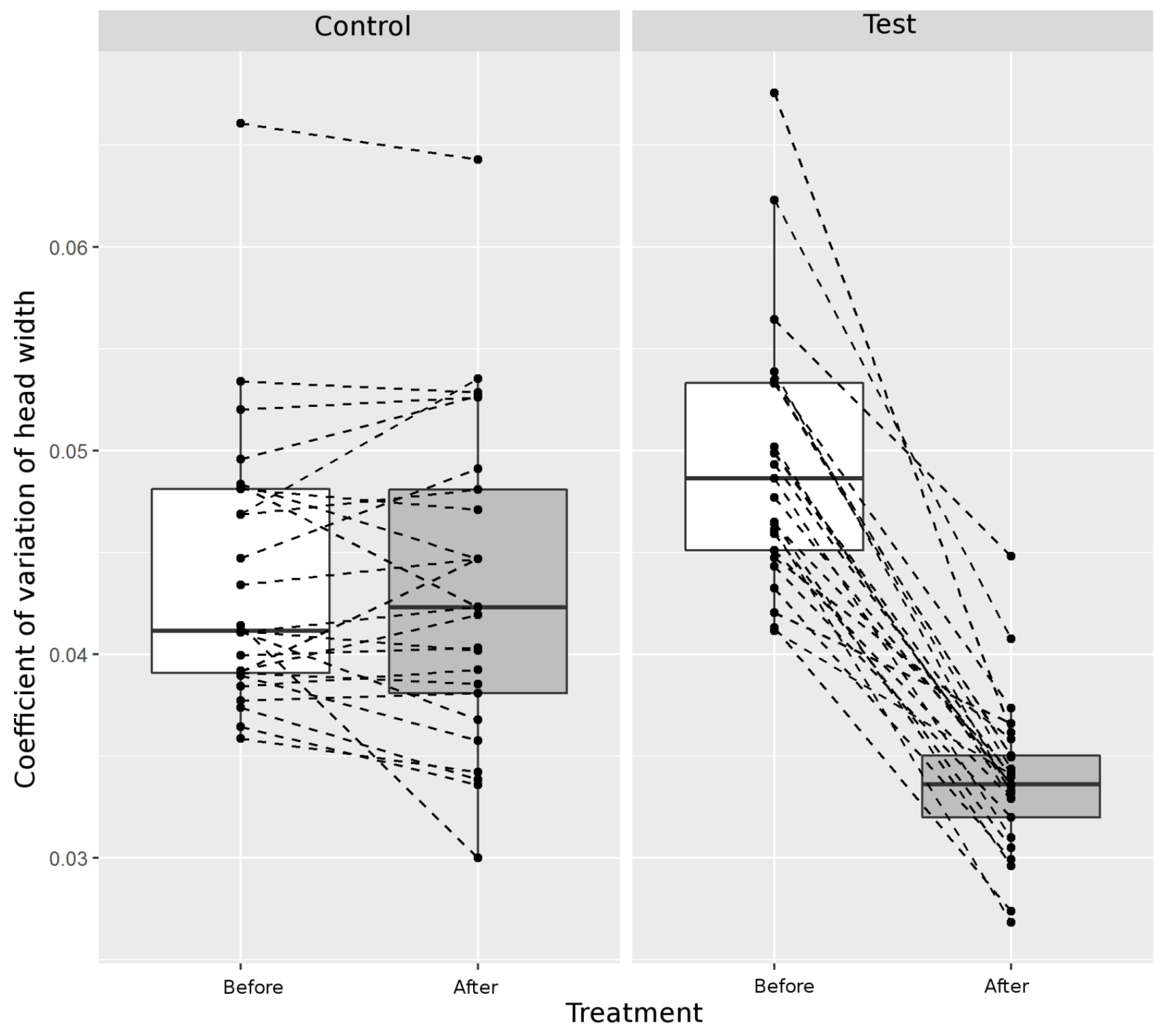


Fig. 2
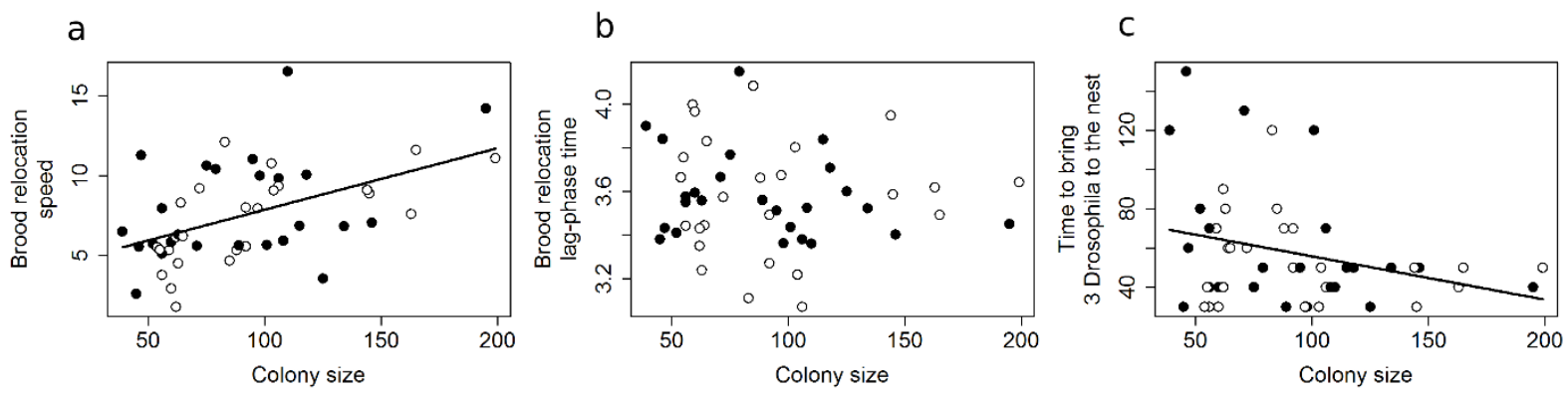

d

e
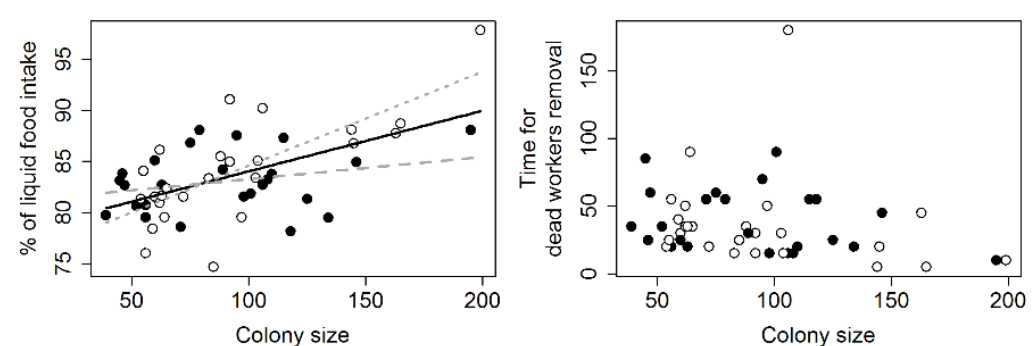

f
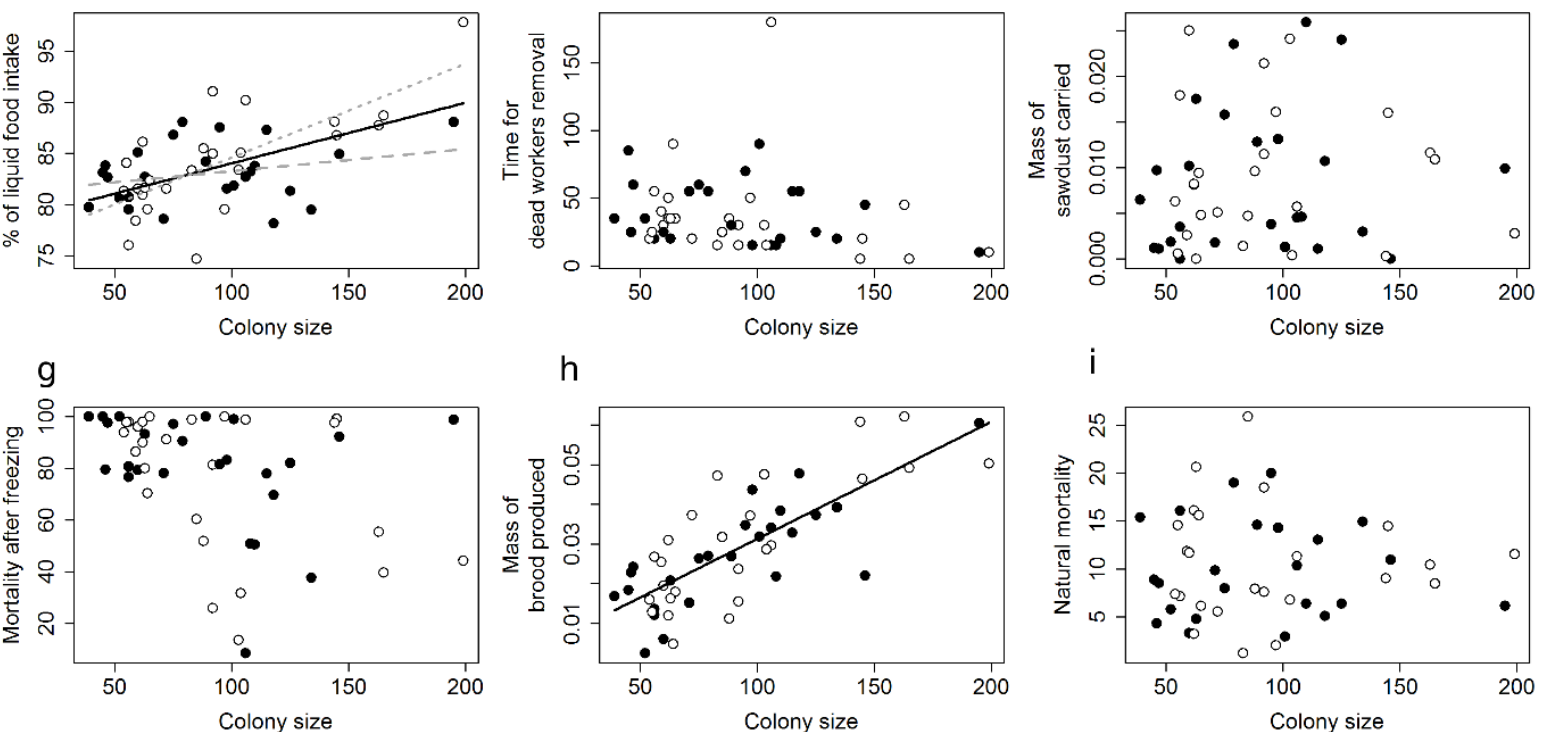

h
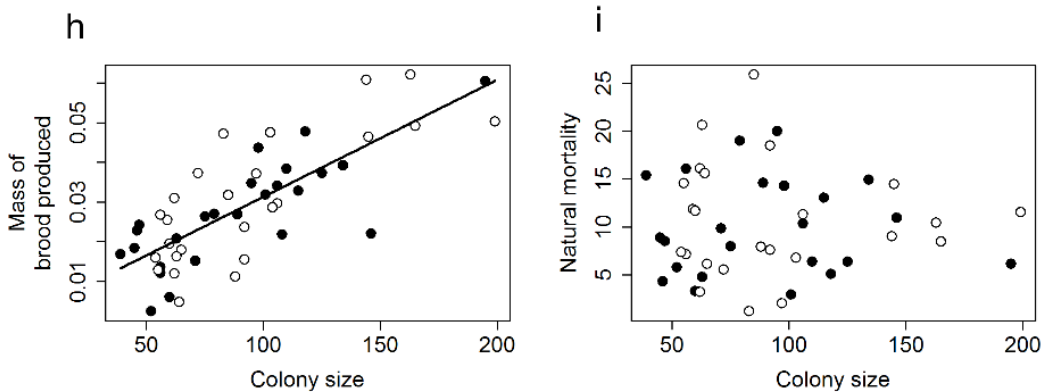


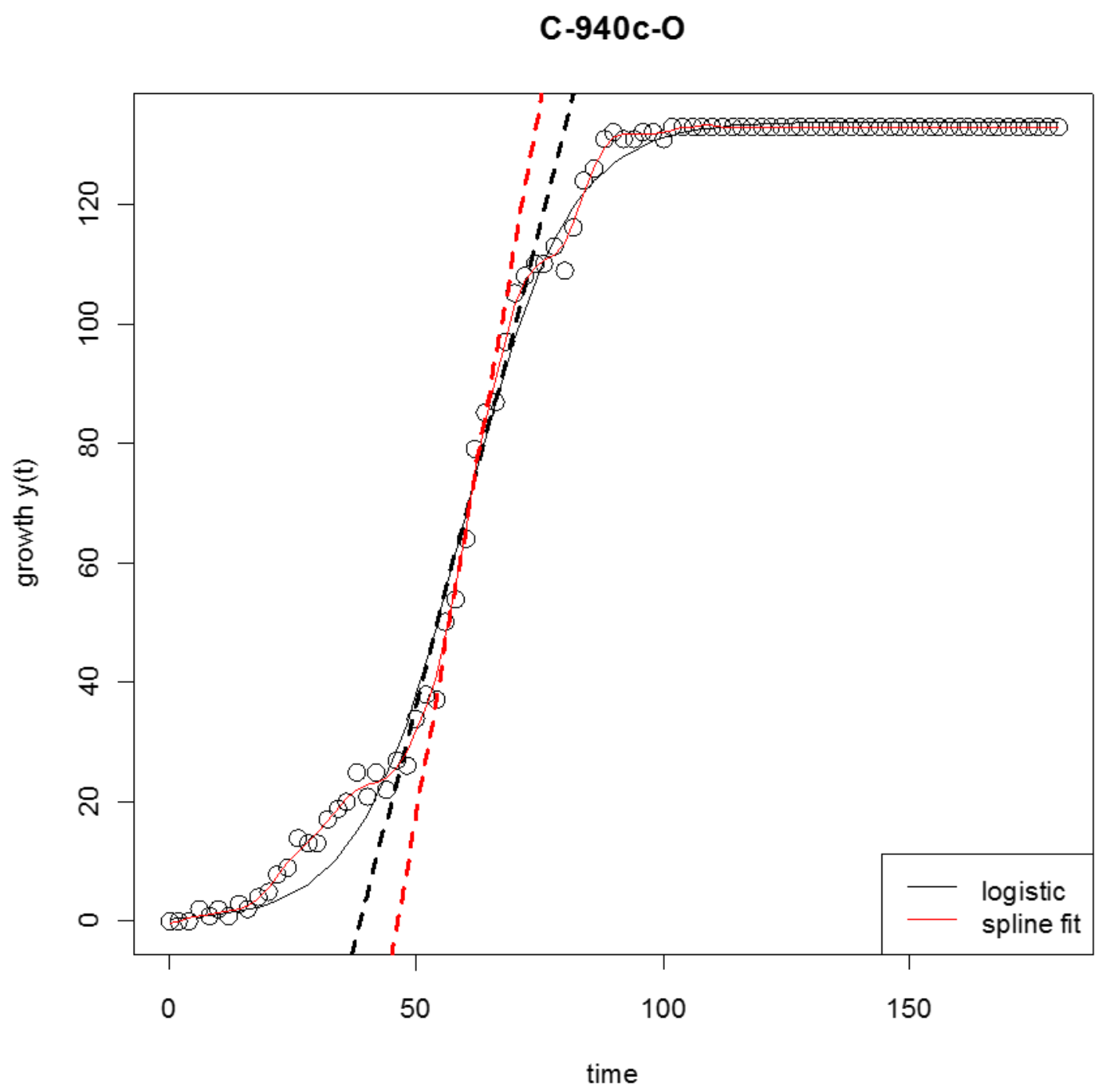

Fig. S1 Example of a logistic fit of the workers' relocation in the colony $n^{\circ} 940$ during the

34 first challenge. Growth $\mathrm{y}(\mathrm{t})$ is the cumulated number of workers in the new nest. $\mu$ is the

35 the slope of the dashed line i.e. the maximum speed of the emigration process. $\lambda$ is the lagphase i.e. the time it took for emigration to start. 